\title{
Mechanical Properties of Laminated Natural Bridge Bearings under Damper and Thermal Condition
}

\author{
Yi ZHENG \\ Liaoning Institute of Building Materials Inspection \\ Liaoning, China \\ e-mail: dandongzy@126.com \\ Yannian ZHANG \\ School of Civil Engineering \\ Shenyang Jianzhu University \\ Liaoning, China \\ e-mail: zyntiger@163.com
}

\author{
Jinqing JIA \\ Faculty of Infrastructure Engineering \\ Dalian University of Technology \\ Liaoning, China \\ e-mail: zgykdxlyn@126.com
}

\author{
Xiaojun SHEN \\ Chongqing highway engineering quality inspection center \\ Chongqing, China \\ e-mail: 58902855@qq.com
}

\author{
Fei GAO \\ Chongqing highway engineering quality inspection center \\ Chongqing, China \\ e-mail: 58902855@qq.com
}

\begin{abstract}
The present study was conducted to obtain a better understanding of the variation rule of compressive mechanical properties of laminated natural bridge bearings under damper and thermal aging condition. A total of 5 specimens were processed in a high-damp and temperature chamber, and one specimen was in natural state. The parameter mainly considered time of damper and thermal aging processing for specimens. The compressive capacity, ultimate compressive strength and compressive elastic modulus of the laminated natural bridge bearings decreased dramatically. The attenuation models conform to reality well which shows that this model is applicable and has vast prospect in assessing the performance of laminated natural bridge bearings under damper and thermal aging condition.
\end{abstract}

Keywords-bridge bearings; damper and thermal aging; compression tests; compressive capacity

\section{INTRODUCTION}

Laminated natural bridge bearings are much easier to install in a bridge than other types of bearings used and require nil maintenance. Such stiffening could be deleterious to bearing. Correctly-designed and suitably-compounded laminated natural bridge bearings can be confidently expected to function efficiently for at least a decade.

Natural has good aging property [1 3], but its physics-mechanical properties deteriorate under thermal aging condition [4]. There is an already vast amount of research into the effects of heating on the behavior of laminated rubber bearings [5 9]. However, there is a lack of the effects of heating on the behavior of laminated natural bridge bearings. The impact of climate is more serious to highway bridge rubber bearings than building rubber bearings.

The present study was then designed to provide a better insight on the variation rule of mechanical properties of laminated natural bridge bearings under damper and thermal aging condition. A total of 5 specimens were processed in a high-damp and temperature chamber. After that, five specimens were tested subjected to axial load. The failure modes and mechanical properties are presented and discussed, and the attenuation trends of ultimate compressive strength and compressive elastic modulus of laminated natural bridge bearings under damper and thermal aging condition are analyzed. Finally, the attenuation models of ultimate compressive strength and compressive elastic modulus laminated natural bridge bearings are acquired by regressing data of experiment with the least square method.

\section{EXPERIMENTAL PROGRAM}

The main goal of the experimental research was to obtain the variation rule of mechanical properties of laminated natural bridge bearings under damper and thermal aging condition.

Fig. 1 shows the shape of a test specimen. The laminated natural bridge bearings are comprised of natural layers and thin steel plates. The specimens are denoted by $\mathrm{GJZL}_{\mathrm{S}} \times \mathrm{L}_{\mathrm{L}} \times \mathrm{T}(\mathrm{NR})$ [10], where GJZ indicates rectangular bridge bearings; $\mathrm{L}_{S}$ is the length of short edges of rectangular bridge bearings; $\mathrm{L}_{\mathrm{L}}$ is the length of long edges of rectangular bridge bearings; $\mathrm{T}$ is the thickness of rectangular bridge 
bearings; $\mathrm{S}$ is the primary shape factor of rectangular bridge bearings; $\Delta l_{1}$ is maximal displacement value regardless of brake force; $\Delta l_{2}$ is maximal displacement value considering of brake force; $t_{e}$ is the total thickness of natural layers; $t_{1}$ is the thickness of a natural layer; $t_{0}$ is the thickness of a steel plate layer. The specification of test specimens in detail is described in Table 1.

All test specimens were made in Chinese Hengshui Xinli Engineering Inc, and the physical and mechanical properties of specimens in detail are described in Table 2.

Fig. 2 shows damper and thermal aging processing of specimens. The specimens were first put in high-temperature test chamber to reach $70^{\circ} \mathrm{C}$ and $60 \mathrm{RH}$. The distance between the samples is greater than $20 \mathrm{~mm}$.

A total of 5 specimens were tested. There were $0,20,40$, 60 and 80 days damper and thermal aging processing for specimens. The Dimensions of specimens have no obvious change after damper and thermal aging processing. Test specimens in detail are described in Table 3.

The compression tests were carried out in the Structural Engineering Laboratory of Shenyang Jianzhu University. The test setup was shown in Fig.3. The compression load was applied by a $5000 \mathrm{kN}$ pressure testing machine.

Strain gauges and displacement sensors arrangement are shown in Fig.4. Strain gauges Y1, Y3, Y5, Y7, Y9 and Y11 measured vertical strain in different parts of specimens, respectively; Strain gauges Y2, Y4, Y6, Y8, Y10 and Y12 measured horizontal strain in different parts of specimens, respectively. Displacement sensors W1 W4 measured the horizontal displacements in different parts of specimens; Displacement sensors W5 and W6 measured the vertical displacements in different parts of specimens.

The specimens were subjected to vertical load, and its loading regimes were described as follows:

(1) The centre of specimens should be adjusted geometrically and physically before preloading. The specimens were loaded to compressive stress $1.0 \mathrm{MPa}$ and displacement sensors were set up.

(2) The specimens were preloaded to permissible compressive stress $[\sigma]$ and keep invariable load 5 minutes. Then, the specimens were unloaded to compressive stress 1.0MPa.

(3) the tests of compressive elastic modulus: The specimens were increased $1.0 \mathrm{MPa}$ every time from compressive stress $1.0 \mathrm{MPa}$ after preloading three times and keep invariable load 3 minutes until the specimens were loaded to $[\sigma]$. Then, the specimens were unloaded to compressive stress $1.0 \mathrm{MPa}$. Loading repeated after 10 minutes, and the loading process continued 3 times.

(4) The tests of ultimate compressive strength: The specimens were increased 1.0MPa every one minute after the tests of compressive elastic modulus until the specimens were loaded to $7[\sigma]$.

TABLE I. SPECIFICATION OF TEST SPECIMENS

\begin{tabular}{|c|c|c|c|c|c|c|c|c|c|}
\hline specimens & $\mathrm{LS} / \mathrm{mm}$ & $\mathrm{LL} / \mathrm{mm}$ & $\mathrm{T} / \mathrm{mm}$ & $S$ & $\Delta 11 / \mathrm{mm}$ & $\Delta 12 / \mathrm{mm}$ & te $/ \mathrm{mm}$ & $\mathrm{t} 1 / \mathrm{mm}$ & $\mathrm{t} 0 / \mathrm{mm}$ \\
\hline GJZ200×300×41(NR) & 200 & 300 & 41 & 7.16 & 12.1 & 16.7 & 28 & 8 & 3 \\
\hline
\end{tabular}

TABLE II. PhySICAL AND MEChaNICAL PROPERTIES OF SPECIMENS

\begin{tabular}{|c|c|c|c|c|c|c|c|}
\hline specimens & $\begin{array}{c}\text { hardness } \\
\text { (IRHD) }\end{array}$ & $\begin{array}{c}\text { tensile } \\
\text { strength } \\
(\mathrm{MPa})\end{array}$ & $\begin{array}{c}\text { elongation at } \\
\text { rupture(\%) }\end{array}$ & $\begin{array}{c}\text { peeling } \\
\text { strength } \\
(\mathrm{kN} / \mathrm{m})\end{array}$ & $\begin{array}{l}\text { ultimate compressive } \\
\text { strength (MPa) }\end{array}$ & $\begin{array}{c}\text { compressive elastic } \\
\text { modulus (MPa) }\end{array}$ & $\begin{array}{l}\text { elastic modulus of } \\
\text { shear (MPa) }\end{array}$ \\
\hline GJZ200×300×41(NR) & 63 & 19 & 458 & 11 & 70 & 712 & 1.01 \\
\hline
\end{tabular}




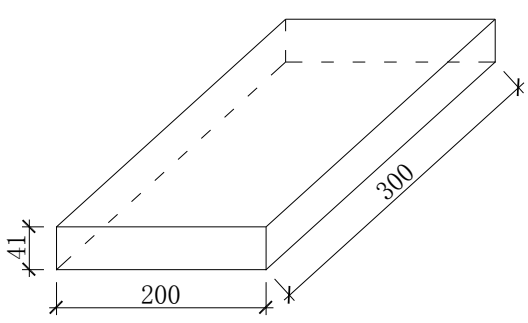

Figure 1. Shape of a test specimen

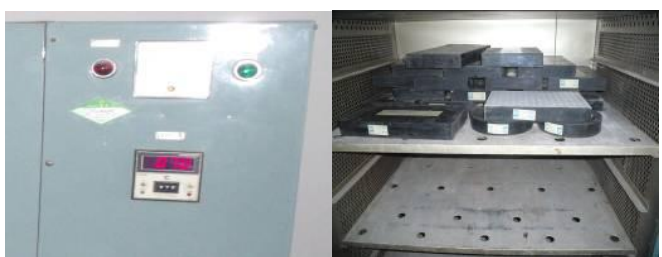

Figure 2. Thermal aging processing of specimens in high-temperature test chamber

TABLE III.

Thermal Aging Processing OF SPECIMENS

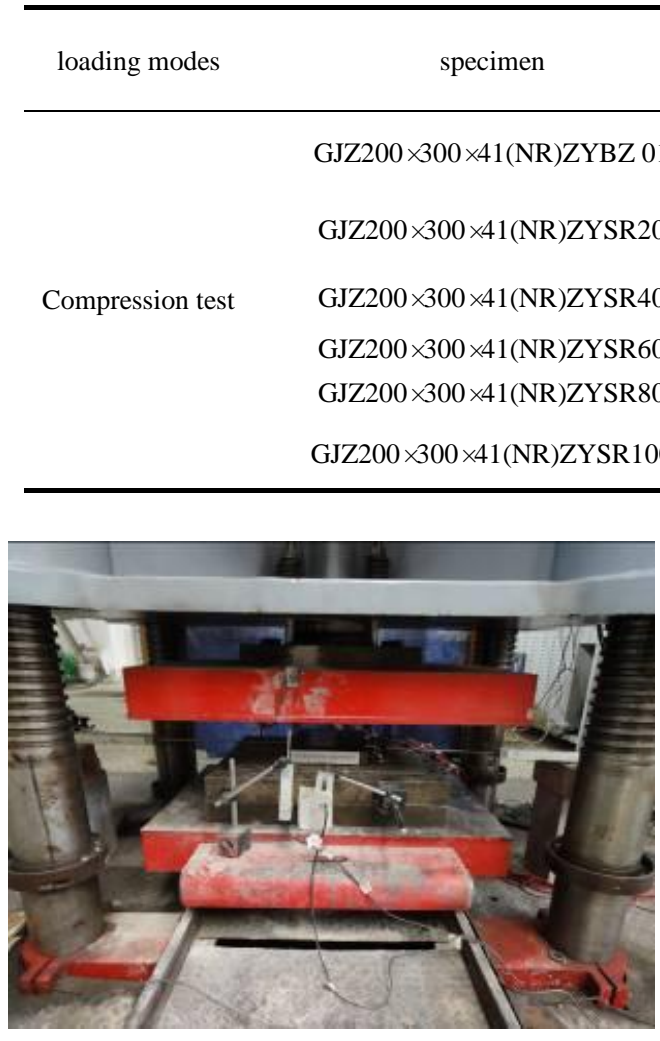

Figure 3. Photograph of compression testing setup

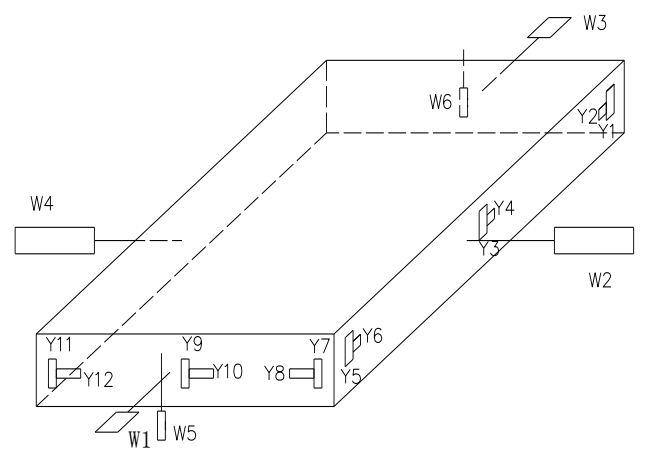

Figure 4. Strain gauges and displacement sensors arrangement of compression test days of thermal Dimensions before thermal Dimensions after thermal aging processing aging processing $(\mathrm{mm}) \quad$ aging processing $(\mathrm{mm})$
0

20

40

60

80

100
$200 \times 300 \times 41$

$200 \times 300 \times 40$

$199 \times 300 \times 42$

$200 \times 300 \times 42$

$200 \times 300 \times 40$

$200 \times 302 \times 41$
$200 \times 300 \times 41$

$199 \times 300 \times 40$

$201 \times 300 \times 41$

$200 \times 301 \times 40$

$200 \times 300 \times 41$

\section{EXPERIMENTAL RESULTS}

Fig. 5 shows failure modes of specimens in compression test. The vertical load increased gradually, specimens were in elastic state when the cracks did not appear. Loading were in a short stagnation when a few fine cracks appeared around agglutinate places of steel plates and rubber of specimens' edge. After that, the vertical displacement increased slowly, but the horizontal displacement increased sharply with load increasing. Meanwhile, protrusions appeared around specimens' edge, and the cracks got larger and deeper fast. The vertical displacement and horizontal displacement increased slowly and load declined precipitously when specimens devastated. The layer-crack damage characteristics of specimens were obvious because steel plates broke away from rubber. The specimens after thermal aging processing were more probably brittle failure than the standard specimen. Moreover, the exposure of steel plate, cracks and other failure phenomena were more serious than the standard specimen.

The mechanical properties of specimens are shown in table 4 . The compressive capacity, ultimate compressive strength and compressive elastic modulus of the specimens decreased obviously with the increasing in time of damper and thermal aging processing. 


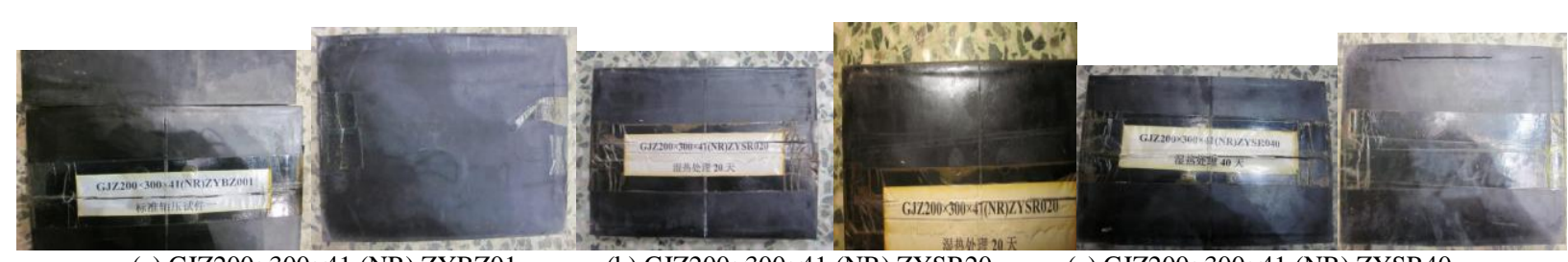

(a) GJZ200×300×41 (NR) ZYBZ01

(b) GJZ200×300×41 (NR) ZYSR20

(c) GJZ200×300×41 (NR) ZYSR40

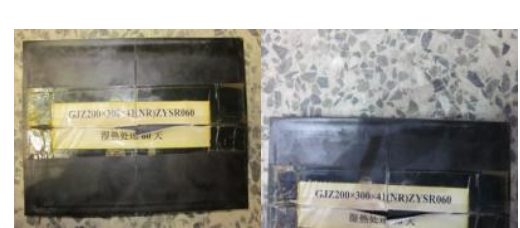

(d) GJZ200×300×41 (NR) ZYSR60

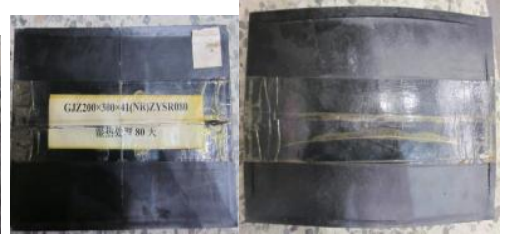

(e) GJZ200×300×41 (NR) ZYSR80

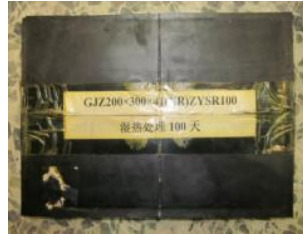

(f) GJZ200×300×41 (NR) ZYSR100

Figure 5. Failure modes of specimens in compression tests

TABLE IV.

The MeChanical Properties OF SPECIMENS IN COMPRESSION TEST

\begin{tabular}{|c|c|c|c|c|c|c|c|c|}
\hline \multirow{2}{*}{ Specimen } & \multirow{2}{*}{$\begin{array}{l}\text { Compressive } \\
\text { capacity }(\mathrm{kN})\end{array}$} & \multirow{2}{*}{$\begin{array}{c}\text { Ultimate } \\
\text { compressive } \\
\text { strength } \\
(\mathrm{MPa})\end{array}$} & \multicolumn{3}{|c|}{$\begin{array}{l}\text { Displacement corresponding to ultimate } \\
\text { compressive strength (mm) }\end{array}$} & \multicolumn{3}{|c|}{$\begin{array}{l}\text { Displacement corresponding to } \\
\text { compressive stress } 70 \mathrm{MPa}(\mathrm{mm})\end{array}$} \\
\hline & & & vertical & $\begin{array}{l}\text { horizontal } \\
\text { longitudinal }\end{array}$ & $\begin{array}{c}\text { horizontal } \\
\text { lateral }\end{array}$ & vertical & $\begin{array}{c}\text { horizontal } \\
\text { longitudinal }\end{array}$ & $\begin{array}{c}\text { horizontal } \\
\text { lateral }\end{array}$ \\
\hline GJZ200×300×41(NR)ZYBZ 01 & 4755.40 & 79.26 & 4.94 & 5.32 & 3.93 & 3.57 & 4.00 & 3.25 \\
\hline GJZ200×300×41(NR)ZYSR20 & 4319.57 & 71.99 & 2.29 & 3.63 & 2.87 & 2.09 & 3.38 & 2.77 \\
\hline GJZ200×300×41(NR)ZYSR40 & 4072.44 & 67.87 & 3.04 & 3.16 & 2.85 & 3.36 & 3.46 & 3.00 \\
\hline GJZ200×300×41(NR)ZYSR60 & 3964.91 & 66.08 & 2.96 & 2.84 & 2.59 & 3.63 & 3.39 & 2.89 \\
\hline GJZ200×300×41(NR)ZYSR80 & 3428.80 & 57.15 & 2.73 & 3.24 & 2.62 & 4.64 & 5.07 & 3.54 \\
\hline GJZ200×300×41(NR)ZYSR 100 & 3308.47 & 55.14 & 2.30 & 2.51 & 2.30 & 4.63 & 4.59 & 3.38 \\
\hline
\end{tabular}

\section{TEST ANALYSIS}

Fig.6 shows the attenuation curve of compressive capacity of laminated natural bridge bearings. The damper and thermal aging processing has a significant impact on compressive capacity of laminated natural bridge bearings. The compressive capacity decreased dramatically with the increasing in aging time.

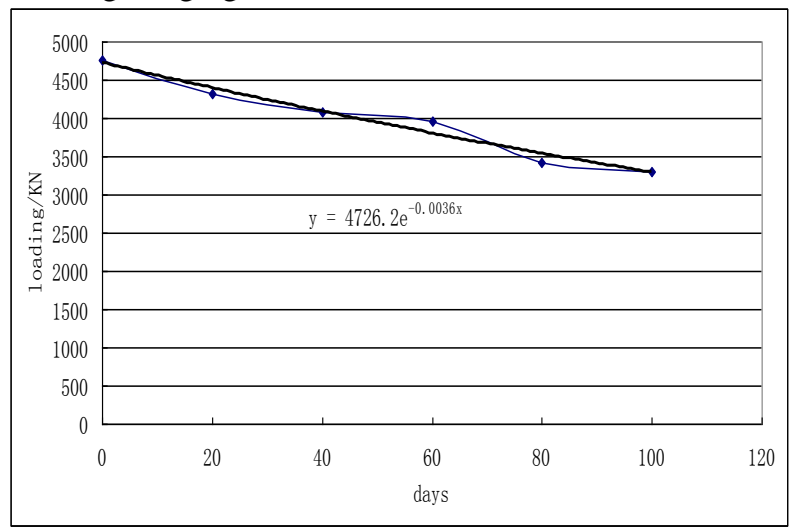

Figure 6 . The attenuation curve of compressive capacity of bearings

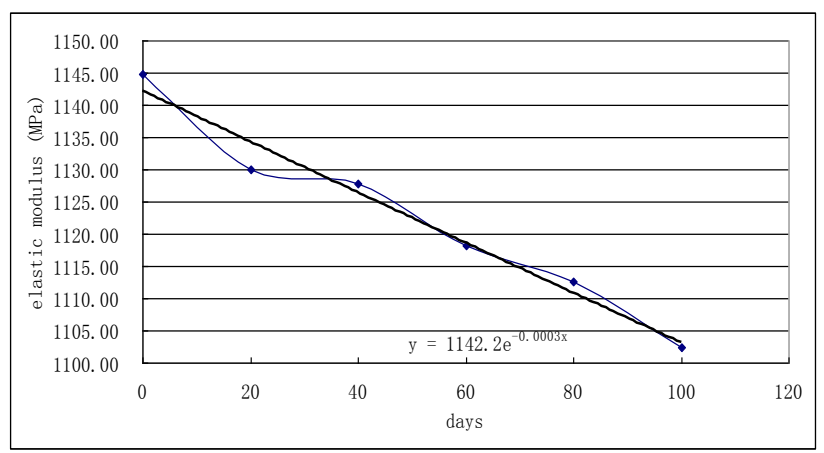

Figure 7. The attenuation curve of compressive elastic modulus 


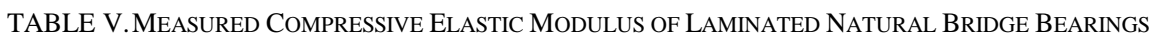

\begin{tabular}{|c|c|}
\hline Specimen & Measured compressive elastic modulus (MPa) \\
\hline GJZ200×300×41(NR)ZYBZ 01 & 1144.81 \\
\hline GJZ200×300×41(NR)ZYSR20 & 1130.00 \\
\hline GJZ200×300×41(NR)ZYSR40 & 1127.70 \\
\hline GJZ200×300×41(NR)ZYSR60 & 1118.18 \\
\hline GJZ200×300×41(NR)ZYSR80 & 1112.57 \\
\hline GJZ200×300×41(NR)ZYSR100 & 1102.42 \\
\hline
\end{tabular}

The average summer temperature in most parts of the world is $20 \sim 35^{\circ} \mathrm{C}$, and humidity is $60 \mathrm{RH}$. Therefore, the average summer temperature is taken as $25^{\circ} \mathrm{C}$, and the average summer humidity is $60 \mathrm{RH}$. Many tests of rubber bearings on Tomei Expressway which made by Japan Highway Public Corporation showed that those ultimate tensile strength, extension rate and shear modulus after thermal aging processing $\left(60 \sim 80^{\circ} \mathrm{C}\right)$ of $1,200 \sim 2,040$ hours would be the equivalent of 100-year thermal aging state at $23^{\circ} \mathrm{C}$ [12]. Moreover, some tests showed that rubber would be at twice speed of thermal aging when temperature was increased $10^{\circ} \mathrm{C}$ [4]. The thermal aging processing of 20,40 , 60 and 80 days at $70^{\circ} \mathrm{C}$ is the equivalent of thermal aging 15 , 30,45 and 60 years in natural environment. The test results show that the attenuation trend of ultimate compressive strength accords with power function. The attenuation model is acquired by regressing data of experiment with the least square method. Fig.6 shows the attenuation curve of ultimate compressive strength of laminated natural bridge bearings. The attenuation function is shown as follows:

$$
y=4726.2 e^{-0.0036 x}
$$

Where, $y$ is ultimate compressive strength; $x$ is years of damper and thermal aging.

The attenuation model of ultimate compressive strength conform to reality well which shows that this model is applicable and has vast prospect in assessing the performance of laminated natural bridge bearings under damper and thermal aging condition.

The computational formula of measured vertical stiffness of laminated natural bridge bearings is shown as follows [13]:

$$
K_{\mathrm{v}}^{\mathrm{T}}=\frac{P_{2}-P_{1}}{Y_{2}-Y_{1}}
$$

Where, $\mathrm{P} 1$ is the minimum pressure at third cyclic loading; $\mathrm{P} 2$ is the maximum pressure at third cyclic loading; Y1 is the minimum displacement at third cyclic loading; $\mathrm{Y} 2$ is the maximum displacement at third cyclic loading.
Fig.7 shows load-vertical stiffness curve of laminated natural bridge bearings. The results show that the damper and thermal aging processing has a relatively little effect on vertical stiffness.

The computational formula of compressive elastic modulus of laminated natural bridge bearings is shown as follows [11]:

$$
E_{1}=\frac{\sigma_{10}-\sigma_{4}}{\varepsilon_{10}-\varepsilon_{4}}
$$

Where, E1 is a calculated value of compressive elastic modulus; $\sigma_{4}$ and $\varepsilon_{4}$ are compressive stress and cumulative compressive strain in the loading stage at $4.0 \mathrm{MPa}$, respectively. $\sigma_{10}$ and $\varepsilon_{10}$ are compressive stress and cumulative compressive strain in the loading stage at 10.0MPa, respectively.

The measured compressive elastic modulus of laminated natural bridge bearings is summarized in Table 5 .

The test results show that the attenuation trend of compressive elastic modulus accords with power function. The attenuation model is acquired by regressing data of experiment with the least square method. The attenuation function is shown as follows:

$$
E=1142.2 e^{-0.0003 x}
$$

Where, $\mathrm{E}$ is compressive elastic modulus.

\section{SUMMARY}

The compression test results show that the specimens after damper and thermal aging processing prone to more brittle failure than the standard specimen. Moreover, the steel plate exposed, cracks and other damage phenomena are more serious than the standard specimen.

With the increasing in the aging time and the deepening of the degree of damper and thermal aging processing, compressive capacity, ultimate compressive strength and compressive elastic modulus of the laminated natural bridge bearings decreased dramatically. 
The test results show that the attenuation trends of ultimate compressive strength and compressive elastic modulus with power function. The attenuation models are acquired by regressing data of experiment with the least square method. The attenuation models conform to reality well which shows that this model is applicable and has vast prospect in assessing the performance of laminated natural bridge bearings under damper and thermal aging condition.

\section{ACKNOWLEDGEMENT}

This research was supported by The Special Fund Project for the Scientific Research of the Quality Control (201210040), Natural Science Foundation Project of Chongqing (CSTC2012jjA0860), Project of Science Research by Chongqing (CSTC2013yykfA30004), Project of Science Research by Shenyang (F12-271-4-00, F12-216-8-00).

\section{REFERENCES}

[1] Wingard. Use of DSC and DMA to study crystallization as a possible cause for a glove tear. Journal of Thermal Analysis and Calorimetry, 102(2010)469-476.

[2] Y. Zheng, J.Q. Jia, X.J. Shen, et al. Safety evaluation method for laminated rubber bearings of bridge based on extension theory. Journal of south china university of technology (natural science edition), 40, (2012)160-164.
[3] H.T. Chiu, P.A. Tsai and T.C. Cheng. Study of rheological behavior and miscibility of epoxidized natural rubber modified neoprene. Journal of Materials Engineering and Performance, 15(2006)81-87.

[4] S.Z.Xie, D.F.Liu, M.L.Zhou. Rubber Industry Manual (Volume I). Beijing: Chemical Industry Press, 1989. (In Chinese)

[5] D.H. Xu, H.F. Wu, J.F. Wang. The affect of the environmental temperature on the neoprene rubber bearings the shear properties. Highway. 1(2010)76-78. (In Chinese)

[6] I.V. Kalpakidis, M.C. Constantinou. Effects of heating on the behavior of lead-rubber bearings. 1: theory. Journal of Structural Engineering, 135(2009)1440-1449.

[7] I.V. Kalpakidis, M.C. Constantinou. Effects of heating on the behavior of lead-rubber bearings. 2: verification of theory, Journal of Structural Engineering, 135(2009) 1450-1461.

[8] Y.F. Du, J.L. Kou, W.W. Kou. Analysis of thermal mechanical of lam inated rubber bearing under high temperature, Sichuan Building Science. 6(2010)150-153. (In Chinese)

[9] G.S. Cheng. The forecast of the aging characteristics of natural bearings in bridge [J]. World bridges. 40(2010)63-65. (In Chinese)

[10] The industrial standard of communications in the People's Republic of China. Series of elastomeric pad bearings for highway bridges (JT/T 663-2006), 2006. (In Chinese)

[11] The industrial standard of communications in the People's Republic of China. Elastomeric pad bearings for highway bridges (JT/T4-2004), 2004. (In Chinese)

[12] M.H. Zhou. Service life and application measures of rubber bearings for highway bridges. World bridges. 2(2004)71-74. (In Chinese)

[13] National Standard of the People's Republic of China. GB 20688.1-2007, Rubber bearings: Part 1, Seismic-protection isolators test. Beijing: Standards Press of China, 2007. (In Chinese) 